\title{
Association between the epidermal growth factor gene polymorphism and endometriosis in women from Brazil
}

\author{
C.B.N. Oliveira ${ }^{1,3}$, P. Falagan-Lotsch ${ }^{1,3}$, M.G. Souza ${ }^{1,3}$, R.P. Santos ${ }^{1}$, \\ F. Encinas ${ }^{2}$, H. Teles ${ }^{2}$, R.B. Lasmar ${ }^{2}$, L.B. Duarte ${ }^{2}$, J.M. Granjeiro' ${ }^{1,3}$ and \\ I.A. Penna ${ }^{1,2}$
}

${ }^{1}$ Centro de Terapia Celular, Unidade de Pesquisa Clínica, Hospital Universitário Antonio Pedro, Universidade Federal Fluminense, Niterói, RJ, Brasil

${ }^{2}$ Departamento Materno-Infantil, Hospital Universitário Antonio Pedro, Universidade Federal Fluminense, Niterói, RJ, Brasil

${ }^{3}$ Laboratório de Biotecnologia, Instituto Nacional de Metrologia,

Qualidade e Tecnologia, Duque de Caxias, RJ, Brasil

Corresponding author: I.A. Penna

E-mail: pennai@vm.uff.br

Genet. Mol. Res. 13 (3): 7239-7245 (2014)

Received May 28, 2013

Accepted June 26, 2014

Published September 5, 2014

DOI http://dx.doi.org/10.4238/2014.September.5.8

\begin{abstract}
The aim of this study was to verify the association between the epidermal growth factor $(E G F)+61 \mathrm{G} / \mathrm{A}$ polymorphism and the susceptibility to endometriosis using a case-control design study. The control group included fertile women without endometriosis and the case group included endometriosis patients. Polymerase chain reaction-restriction fragment length polymorphism analysis was used to genotype the $E G F+61 \mathrm{G} / \mathrm{A}$ polymorphism. Initially, a total of 184 individuals were analyzed. After matching by ethnicity, the control group was composed of 57 individuals, while the endometriosis group was composed of 57 patients. No statistically significant associations were observed between $E G F+61$ variants and the risk of endometriosis development $(\mathrm{P}>0.05)$. This is the first study correlating the $E F G$
\end{abstract}


$+61 \mathrm{G} /$ A polymorphism and endometriosis in women from Brazil, and demonstrates that $E F G+61 \mathrm{G} / \mathrm{A}$ is not associated with endometriosis susceptibility in Brazilian women.

Key words: Endometriosis; Epidermal growth factor; Polymorphism

\section{INTRODUCTION}

Endometriosis is an estrogen-dependent gynecological disorder associated with pelvic pain and infertility. It is characterized by the presence of uterine endometrial tissue (glands and stroma) outside the uterine cavity (Giudice and Kao, 2004), most commonly the ovaries and peritoneum (Prowse et al., 2006). Endometriosis affects up to $10 \%$ of women in their reproductive years (Giudice and Kao, 2004; Kennedy et al., 2005; Prowse et al., 2006; Romualdi et al., 2011).

The pathophysiology of endometriosis is unclear. Numerous hypotheses have been proposed to explain the presence of ectopic endometrial tissue (Bianco et al., 2012; Bellelis et al., 2011), but 2 main hypotheses have been cited: the metaplasia theory proposed by Meyer in 1919 and the retrograde menstruation theory proposed by Sampson in 1921. The latter theory is the most widely accepted. Endocrine, immune, and environmental factors have been also suggested to be involved in the pathogenesis (Falconer et al., 2007). In addition, a genetic factor, defined as a kinship factor, with maternal and paternal inheritance, appears to be involved in the susceptibility to disease (Stefansson et al., 2002). More than 20 candidate genes, including transforming growth factor, interleukin, estrogen receptor, progesterone receptor, 17- $\beta$ hydroxysteroid dehydrogenase, and growth factor genes, have been associated with endometriosis risk (Falconer et al., 2007).

The endometrium is a tissue that renews itself every 28 days. Several growth factors present in this tissue participate in this process, including epidermal growth factor (EGF) (Möller et al., 2001). EGF is a single polypeptide chain of 53 amino acid residues and plays a role in many processes such as DNA synthesis, mitogenesis, and proliferation of many cell types (Carpenter and Cohen, 1979, 1990), including endometrial cells (Haining et al., 1991; Giudice, 1994). The addition of EGF protein to a primary cell culture of endometriotic cells significantly increased DNA synthesis (Taketani and Mizuno, 1992).

A functional polymorphism (rs4444903) at position 61 in the 5 '-untranslated region of the $E G F$ gene is characterized by a substitution of guanine (G) for adenine (A). In cells from individuals with the AA genotype, EGF production levels are lower than in cells from individuals with the GG or AG genotypes (Shahbazi et al., 2002).

In this study, we investigated the association between the $E G F+61 \mathrm{G} / \mathrm{A}$ polymorphism and susceptibility to endometriosis in women from Rio de Janeiro, Brazil.

\section{MATERIAL AND METHODS}

\section{Subjects}

The study was approved by the local Ethical Committee (CEP CMM/HUAP No. $122 / 09$ ) and written informed consent was obtained from all participants. All study subjects were recruited from 2009-2011. 
Initially, a total of 68 Brazilian women with histopathological diagnosis of endometriosis were recruited from the Hospital Universitário Antonio Pedro - Niterói, RJ. The inclusion criteria for the endometriosis group were: patients aged 18-45 years who were diagnosed with endometriosis and pelvic peritoneal through postsurgical histopathological evaluation. Exclusion criteria included: patients with decompensate systemic diseases and patients that could not undergo surgery and/or histopathology. The control group included 116 healthy and fertile women in puerperium recruited from the Doctor Alzira Reis Maternity Hospital - Niterói, RJ.

Control group inclusion criteria were: pregnant, aged 18-45 years and without previous pelvic pain or dysmenorrhea. The exclusion criteria were pregnancy with fetal malformations and a history of miscarriage. The subjects were classified as Caucasian and Afro-descendants women as well as those of mixed race based on self-reported information. After the first statistical analysis, both groups were matched with regard to ethnicity to avoid a possible bias in the association analysis between the $E G F$ polymorphism and disease. After matching, each group was composed of 57 women.

\section{$E G F+61 \mathrm{~A} / \mathrm{G}$ genotyping}

Genomic DNA was extracted from saliva samples based on methods described by Küchler et al. (2012), and only samples showing an A260/A280 ratio >1.7 were further examined.

The $E G F+61 \mathrm{~A} / \mathrm{G}$ polymorphism was analyzed using a polymerase chain reaction (PCR)-restriction fragment length polymorphism (RFLP) assay as described by Shabazi et al. (2002). Two primers were used (forward: TGTCACTAAAGGAAAGGAGGT; and reverse: TTCACAGAGTTTAACAGCCC) to amplify a 242-bp fragment. For the PCR, approximately 200 ng genomic DNA was mixed with $0.6 \mu \mathrm{M}$ of each specific primer (Invitrogen; Carlsbad, $\mathrm{CA}, \mathrm{USA}$ ) in a total volume of $30 \mu \mathrm{L}$ containing $0.2 \mathrm{mM} \mathrm{MgCl}_{2}, 2 \mathrm{mM}$ of each dNTP (Fermentas; Vilnius, Lithuania), and 1 U Dream Taq DNA polymerase (Fermentas). Amplification was performed using the following parameters: initial denaturing cycle of $95^{\circ} \mathrm{C}$ for $5 \mathrm{~min}, 44$ cycles consisting of 3 steps: $95^{\circ} \mathrm{C}$ for $30 \mathrm{~s}, 61^{\circ} \mathrm{C}$ for $30 \mathrm{~s}$, and $72^{\circ} \mathrm{C}$ for $1 \mathrm{~min}$. A final extension step at $72^{\circ} \mathrm{C}$ for $10 \mathrm{~min}$ was performed. PCR products were digested overnight at $37^{\circ} \mathrm{C}$ with $2 \mathrm{U}$ of $A l u \mathrm{I}$ (New England Biolabs; Ipswich, MA, USA) restriction enzyme. The restriction fragments were than analyzed by electrophoresis on a $2.5 \%$ agarose gel stained with GelRed (Biotium Inc.; Hayward, CA, USA) and photographed under ultraviolet illumination. The restriction enzyme $A l u \mathrm{I}$ cut the 242-bp PCR products containing the G allele into 15-, 34-, and 193-bp fragments; the PCR products containing the A allele produced 15-, 34-, 91-, and 102bp fragments.

\section{Statistical analysis}

The allelic and genotype frequency distributions for the $E G F$ polymorphism in patients with endometriosis and controls were compared applying the $\chi^{2}$ or Fisher exact test, and mean ages were compared between cases and controls using the Student $t$-test. The GraphPad InStat software (version 3.05 GraphPad Software Inc., 2000) was used for all statistical analyses. Odds ratios (ORs) and $95 \%$ confidence intervals (95\% CIs) were calculated to assess the relationship between the polymorphism and endometriosis susceptibility. A value of $\mathrm{P}<$ 0.05 was considered to be statistically significant. Moreover, Hardy-Weinberg equilibrium 
was tested using the $\chi^{2}$ test, comparing the observed $v s$ the expected genotype frequencies.

\section{RESULTS}

The 2 groups were significantly different regarding mean age $(\mathrm{P}<0.0001)$; in the endometriosis cases, mean age was $34.75 \pm 6.19$ years, while that in the control group was $24.19 \pm 4.75$ years.

The distribution according to ethnicity based on skin color in each group was $64.9 \%$ (37/57) Caucasian, 28.1\% (16/57) mixed race, and 7\% (4/57) Afro-descendant women (Table 1).

\begin{tabular}{|c|c|c|c|}
\hline Characteristics & Endometriosis cases $(\mathrm{N}=57)$ & Control $(\mathrm{N}=57)$ & $\mathrm{P}$ \\
\hline $\begin{array}{l}\text { Age (years) } \\
\text { Ethnicity }^{\mathrm{b}}\end{array}$ & $34.75 \pm 6.19$ & $24.19 \pm 4.75$ & $<0.0001^{*}$ \\
\hline Caucasians & $37(64.9)$ & $37(64.9)$ & \\
\hline Mixed Race & $16(28.1)$ & $16(28.1)$ & \\
\hline Afro-descendants & $04(7)$ & $04(7)$ & \\
\hline Stages $\mathrm{b}, \mathrm{c}$ & & & \\
\hline Stages I and II & $08(14)$ & - & \\
\hline Stages III and IV & $42(77.2)$ & - & \\
\hline
\end{tabular}

${ }^{\mathrm{a}}$ Data are reported as means $\pm \mathrm{SD}$; adifferences between groups were assessed by the Student $t$-test; ${ }^{\mathrm{b}}$ data are reported as $\mathrm{N}(\%)$; ${ }^{\mathrm{c}}$ data missing from five endometriosis case subjects. ${ }^{*}$ Significant at $\mathrm{P}<0.05$.

The genotype frequencies were $17.5 \% \mathrm{AA}, 57.9 \% \mathrm{AG}$, and $24.6 \% \mathrm{GG}$ among endometriosis cases and 22.8\% AA, 57.9\% AG, and 19.3\% GG among controls (Table 2).

The A allele frequencies were similar between cases and controls ( $46.5 \%$ in endometriosis cases and $51.8 \%$ in controls) (Table 2).

Table 2. Allele and genotype frequencies distribution of endometriosis cases and controls.

\begin{tabular}{|c|c|c|c|c|c|}
\hline SNP & Endometriosis cases & Controls & $\chi^{2}$ & OR $(95 \% \mathrm{CI})$ & $\mathrm{P}$ \\
\hline \multicolumn{6}{|l|}{$\overline{E G F+61}$} \\
\hline Genotypes (N, \%) & 57 & 57 & 0.7513 & & 0.6868 \\
\hline $\mathrm{AA}$ & $10(17.5)$ & $13(22.8)$ & & - & \\
\hline $\mathrm{AG}$ & $33(57.9)$ & $33(57.9)$ & & $1.300(0.500-3.380)$ & 0.6348 \\
\hline GG & $14(24.6)$ & $11(19.3)$ & & $1.655(0.528-5.183)$ & 0.5639 \\
\hline $\mathrm{GG}+\mathrm{AG}$ & $47(82.5)$ & $44(77.2)$ & & $1.389(0.552-3.490)$ & 0.6514 \\
\hline \multicolumn{6}{|l|}{ Allele (N, \%) } \\
\hline A & $53(46.5)$ & $59(51.8)$ & & & \\
\hline G & $61(53.5)$ & $55(48.2)$ & & $1.235(0.734-2.077)$ & 1.235 \\
\hline
\end{tabular}

$\mathrm{SNP}=$ single nucleotide polymorphism; $\mathrm{CI}=$ confidence interval; $\mathrm{OR}=$ odds ratio. Differences between groups were assessed by $\chi^{2}$ test and/or the Fisher exact test.

There were no differences in the allelic and genotype frequencies of the $E G F+61 \mathrm{G} / \mathrm{A}$ polymorphism between endometriosis cases and controls.

Genotype distributions were consistent with those predicted based on Hardy-Weinberg equilibrium $(\mathrm{P}>0.05)$.

When cases were divided into subgroups, we observed that $8(14 \%)$ women had stage I or II endometriosis, while 44 women $(77.2 \%)$ had stage III or IV (Table 1). The genotype 
frequencies were $75 \% \mathrm{AG}$ and $25 \% \mathrm{GG}$ in in the stage I and II subgroup and were $22.7 \%$ AA, $52.3 \% \mathrm{AG}$, and $25 \% \mathrm{GG}$ in the stage III and IV group. The allelic distribution was not significantly different between the case and control groups $(\mathrm{P}=0.4302)$; the frequency of the A allele was $37.5 \%$ in the stage I and II subgroup and was $48.9 \%$ in the stage III and IV subgroup (Table 3).

\begin{tabular}{|c|c|c|c|c|}
\hline \multirow{2}{*}{$\begin{array}{l}\text { SNP } \\
E G F+61\end{array}$} & \multicolumn{2}{|c|}{ Endometriosis cases } & \multirow[t]{2}{*}{ OR $(95 \% \mathrm{CI})$} & \multirow[t]{2}{*}{$\mathrm{P}$} \\
\hline & Stages I and II $(\mathrm{N}=8)$ & Stages III and IV $(\mathrm{N}=44)$ & & \\
\hline \multicolumn{5}{|c|}{ Allele (N, \%) } \\
\hline A & $6(37.5)$ & $43(48.9)$ & 0.6279 & \\
\hline G & $10(62.5)$ & $45(51.1)$ & $0.6279(0.210-1.877)$ & 0.4302 \\
\hline
\end{tabular}

\section{DISCUSSION}

Endometriosis is an estrogen-dependent gynecological disorder characterized by the presence of endometrium tissue in extrauterine sites (Barbosa et al., 2012; Rahmioglu et al., 2012). The prevalence in the general population is not completely known but it has been estimated that approximately 176 million women worldwide are affected by the disease (Nnoaham et al., 2011) and more than $97 \%$ of these women are Caucasian (Bellelis et al., 2010).

EGF and its receptor (EGFR) are involved in many cellular functions, including cell proliferation, differentiation, motility, survival, and tissue development (Wang et al., 2008). These factors are present in the human endometrium, and some studies have shown that EGF and EGFR are often expressed in women with normal endometria (Möller et al., 2001). In vitro studies demonstrated that some growth factors, including EGF, can stimulate the proliferation of endometrial cells; moreover, it is thought that these factors may increase the implantation of endometrial cells. Thus, secretion of these factors is likely very important in the development and maintenance of ectopic tissue (Matalliotakis et al., 2003).

Genetic variations in the $E G F$ gene may contribute to differences in its expression and consequently affect disease susceptibility (Wang et al., 2008). The $E G F+61 \mathrm{~A} / \mathrm{G}$ polymorphism appears to have functional significance by increasing the production of EGF in a culture of peripheral blood mononuclear cells. Moreover, it has been associated with several types of cancer, such as pancreatic cancer (Wu et al., 2010), melanoma (Shahbazi et al., 2002), gliomas, and ovarian cancer, where it was shown that the presence of the G allele may be a protective factor for the development of this type of cancer (Araujo et al., 2009). Studies have shown that ovarian cancer may be related to endometriosis (Brinton et al., 1997, 2004; Meng et al., 2011); thus, the $+61 \mathrm{~A} / \mathrm{G} E G F$ polymorphism may be involved in the mechanism of endometriosis development.

In this study, we hypothesized that the polymorphism $+61 \mathrm{~A} / \mathrm{G}$ of the $E G F$ gene may be involved in the pathogenesis of endometriosis in the Brazilian population from Rio de Janeiro.

Comparison of groups before matching by ethnicity showed a statistically significant difference $(\mathrm{P}<0.0001)$, suggesting that different ethnicities (Caucasian/Afro-descendants/ mixed race) may influence the results; thus, to avoid possible bias in the comparison of groups, 
women were matched according to ethnicity based on skin color. Rio de Janeiro is located in the southeastern region of Brazil and is the most densely populated and industrialized region of the country. The population is comprised of an ethnic admixture of Caucasians (European descent, 53.6\%) and people of African descent (mixed European, 33.6\% or potentially mixed African, 12.3\%). The remaining $0.5 \%$ of the population is of Amerindian or Asian descent (IBGE - Instituto Brasileiro de Geografia e Estatística, 2007; Pena et al., 2011).

Our results revealed no correlation between the $E G F+61 \mathrm{~A} / \mathrm{G}$ polymorphism and endometriosis, which agrees with the results of a previous study (Inagaki et al., 2007), which was the only previous association study analyzing endometriosis and the $E G F+61 \mathrm{~A} / \mathrm{G}$ polymorphism. The previous study also found no statistical significance when comparing allele and genotype frequencies of the $E G F+61 \mathrm{~A} / \mathrm{G}$ in endometriosis cases and controls in a Japanese population.

The Brazilian population is genetically heterogeneous. This mixture has clinical significance and implications for the design and interpretation of clinical trials, practice of clinical genetics, and genomic medicine (Pena et al., 2011). Thus, the extrapolation of data from other homogeneous populations may not apply to our population. The Japanese population is relatively genetically homogenous, which likely explains why the results obtained by Inagaki et al. (2007) were not observed in our predominantly heterogeneous population of Brazilians.

In the Japanese population, the genotype GG was the most prevalent, whereas in our study, the most frequently observed genotype was AG, demonstrating that our population was heterogeneous. In subgroup analysis, we found no significant difference between genotypes and allelic frequencies of women with stage I and II and women with stages III and IV endometriosis. For women in stages I and II in our study, the AA genotype was not observed; stages III and IV were the most common in our population. These results corroborate those of the Japanese study, which also found that stages III and IV were more common.

In summary, we did not observe an interaction between the $E G F+61 \mathrm{~A} / \mathrm{G}$ polymorphism and the susceptibility to endometriosis in our Brazilian population. The small sample size limits the strength of this study, so further studies using larger sample sizes are needed to confirm the role of the $E F G+61 \mathrm{~A} / \mathrm{G}$ polymorphism in the genetic susceptibility to endometriosis.

\section{ACKNOWLEDGMENTS}

The authors are grateful to Fundação de Amparo à Pesquisa do Estado do Rio de Janeiro (FAPERJ, \#E-26/110.079/2010), Coordenação de Aperfeiçoamento de Pessoal de Nível Superior (CAPES), Conselho Nacional de Desenvolvimento Científico e Tecnológico (CNPq), and Departamento de Ciência e Tecnologia (DECIT/MS) for financial support.

\section{REFERENCES}

Araujo AP, Ribeiro R, Pereira D, Pinto D, et al. (2009). Ovarian cancer and genetic susceptibility: association of A61G polymorphism in the EGF gene. Exp. Biol. Med. 234: 241-245.

Barbosa CP, Teles JS, Lerner TG, Peluso C, et al. (2012). Genetic association study of polymorphisms FOXP3 and FCRL3 in women with endometriosis. Fertil. Steril. 97: 1124-1128.

Bellelis P, Dias JA Jr., Podgaec S, Gonzales M, et al. (2010). Epidemiological and clinical aspects of pelvic endometriosis - a case series. Rev. Assoc. Med. Bras. 56: 467-471.

Bellelis P, Podgaec S and Abrao MS (2011). Environmental factors and endometriosis. Rev. Assoc. Med. Bras. 57: 448452. 
Bianco B, Andre GM, Vilarino FL, Peluso C, et al. (2012). The possible role of genetic variants in autoimmune-related genes in the development of endometriosis. Hum. Immunol. 73: 306-315.

Brinton LA, Gridley G, Persson I, Baron J, et al. (1997). Cancer risk after a hospital discharge diagnosis of endometriosis. Am. J. Obstet. Gynecol. 176: 572-579.

Brinton LA, Lamb EJ, Moghissi KS, Scoccia B, et al. (2004). Ovarian cancer risk associated with varying causes of infertility. Fertil. Steril. 82: 405-414.

Carpenter G and Cohen S (1979). Epidermal growth factor. Annu. Rev. Biochem. 48: 193-216.

Carpenter G and Cohen S (1990). Epidermal growth factor. J. Biol. Chem. 265: 7709-7712.

Falconer H, D'Hooghe T and Fried G (2007). Endometriosis and genetic polymorphisms. Obstet. Gynecol. Surv. 62: 616-628.

Giudice LC (1994). Growth factors and growth modulators in human uterine endometrium: their potential relevance to reproductive medicine. Fertil. Steril. 61: 1-17.

Giudice LC and Kao LC (2004). Endometriosis. Lancet 364: 1789-1799.

Haining RE, Cameron IT, van Papendorp C, Davenport AP, et al. (1991). Epidermal growth factor in human endometrium: proliferative effects in culture and immunocytochemical localization in normal and endometriotic tissues. Hum. Reprod. 6: 1200-1205.

IBGE - Instituto Brasileiro de Geografia e Estatística (2007). SIDRA - Pesquisa Nacional por Amostra de Domicílios, Síntese de Indicadores, Rio de Janeiro.

Inagaki M, Yoshida S, Kennedy S, Takemura N, et al. (2007). Association study between epidermal growth factor receptor and epidermal growth factor polymorphisms and endometriosis in a Japanese population. Gynecol. Endocrinol. 23: 474-478.

Kennedy S, Bergqvist A, Chapron C, D'Hooghe T, et al. (2005). ESHRE guideline for the diagnosis and treatment of endometriosis. Hum. Reprod. 20: 2698-2704.

Küchler EC, Tannure PN, Falagan-Lotsch P, Lopes TS, et al. (2012). Buccal cells DNA extraction to obtain high quality human genomic DNA suitable for polymorphism genotyping by PCR-RFLP and Real-Time PCR. J. Appl. Oral Sci. 20: 467-471.

Matalliotakis IM, Goumenou AG, Koumantakis GE, Neonaki MA, et al. (2003). Serum concentrations of growth factors in women with and without endometriosis: the action of anti-endometriosis medicines. Int. Immunopharmacol. 3: 81-89.

Meng Q, Sun W, Jiang J, Fletcher NM, et al. (2011). Identification of common mechanisms between endometriosis and ovarian cancer. J. Assist. Reprod. Genet. 28: 917-923.

Meyer R (1919). Uber den staude der frage der adenomyosites adenomyoma in allgemeinen und adenomyonetitis sarcomatosa. Zentralbl. Gynakol. 36: 745-759.

Möller B, Rasmussen C, Lindblom B and Olovsson M (2001). Expression of the angiogenic growth factors VEGF, FGF2, EGF and their receptors in normal human endometrium during the menstrual cycle. Mol. Hum. Reprod. 7: 65-72.

Nnoaham KE, Hummelshoj L, Webster P, D'Hooghe T, et al. (2011). Impact of endometriosis on quality of life and work productivity: a multicenter study across ten countries. Fertil. Steril. 96: 366-373.

Pena SD, Di Pietro G, Fuchshuber-Moraes M, Genro JP, et al. (2011). The genomic ancestry of individuals from different geographical regions of Brazil is more uniform than expected. PLoS One 6: e17063.

Prowse AH, Manek S, Varma R, Liu J, et al. (2006). Molecular genetic evidence that endometriosis is a precursor of ovarian cancer. Int. J. Cancer 119: 556-562.

Rahmioglu N, Missmer SA, Montgomery GW and Zondervan KT (2012). Insights into Assessing the Genetics of Endometriosis. Curr. Obstet. Gynecol. Rep. 1: 124-137.

Romualdi D, Franco ZG, Lanzone A, Selvaggi L, et al. (2011). Follicular loss in endoscopic surgery for ovarian endometriosis: quantitative and qualitative observations. Fertil. Steril. 96: 374-378.

Sampson JA (1921). Perforating hemorrhagic cysts of the ovary, their importance and especially their relation to pelvic adenomas of endometrial type. Arch. Surg. 3: 245-247.

Shahbazi M, Pravica V, Nasreen N, Fakhoury H, et al. (2002). Association between functional polymorphism in EGF gene and malignant melanoma. Lancet 359: 397-401.

Stefansson H, Geirsson RT, Steinthorsdottir V, Jonsson H, et al. (2002). Genetic factors contribute to the risk of developing endometriosis. Hum. Reprod. 17: 555-559.

Taketani Y and Mizuno M (1992). Hormonal regulation of the cell growth in an endometriotic cell culture system. Arch Gynecol. Obstet. 251: 29-34.

Wang Y, Tian T, Hu Z, Tang J, et al. (2008). EGF promoter SNPs, plasma EGF levels and risk of breast cancer in Chinese women. Breast Cancer Res. Treat. 111: 321-327.

Wu GY, Lu Q, Hasenberg T, Niedergethmann M, et al. (2010). Association between EGF, TGF-\{beta\}1, TNF-\{alpha\} gene polymorphisms and cancer of the pancreatic head. Anticancer Res. 30: 5257-5261. 